\title{
Beta-blockade in the treatment of hypertrophic cardiomyopathy
}

\author{
M.M. Webb-Peploe
}

Department of Cardiology, St. Thomas' Hospital, London SE1 7EH, UK.

\section{Introduction}

In considering the role of any drug in the treatment of hypertrophic cardiomyopathy, the following aspects of the condition and their response to the drug have to be considered separately. 1. Ventricular emptying, i.e. outflow tract obstruction. 2. Ventricular filling, i.e. ventricular compliance. 3 . Ventricular relaxation, i.e. pressure fall during the isovolumic period of relaxation. 4. Regression of hypertrophy. 5. Arrhythmias.

\section{Ventricular emptying}

The early studies on hypertrophic cardiomyopathy suggest that outflow tract obstruction was the essential feature of the disease. It was soon realized that the outflow tract gradient was labile and could be manipulated by a variety of physiological and pharmacological means (Braunwald et al., 1960; Wigle, 1964; Goodwin et al., 1964). Thus, it is now well recognized that obstruction is increased by manoeuvres that increase contractility, by a decrease in left ventricular after-load and by a decrease in left ventricular filling.

Beta-receptor antagonist drugs, by decreasing contractility and by blocking peripheral dilator betaendings, and thus causing peripheral constriction, have a dual mode of decreasing left ventricular outflow tract obstruction. Because their effect at the periphery is also of importance we would expect cardioselective beta-blocking drugs to be less effective than the non-selective ones at reducing outflow tract obstruction, and this has, in general, been our experience in the catheter laboratory (Goodwin et al., 1964; Braunwald et al., 1964; Swanton et al., 1977).

\section{Ventricular filling}

Left ventricular end-diastolic pressure is often elevated in hypertrophic cardiomyopathy and the degree of

Correspondence: M.M. Webb-Peploe, F.R.C.P. elevation correlates positively with symptoms and possibly also with prognosis (Swan et al., 1971). In a study looking at responses to isoprenaline infusion and exercise, we showed that left ventricular enddiastolic pressure is usually raised, and that it increases further in response to both exercise and isoprenaline infusion (Webb-Peploe et al., 1971; Webb-Peploe, 1974). This was not simply a rate effect, since pacing to equivalent heart rates, if anything, reduced enddiastolic pressure. Following the administration of the selective beta-adrenergic blocking agent, practolol, the left ventricular end-diastolic pressure fell and end diastolic volume increased, suggesting improvement in diastolic function, with increased distensibility of the ventricle and an increase in compliance. These effects were strikingly different from those in patients with ischaemic heart disease, dilated cardiomyopathy and in patients who appear to have normal hearts. In these the expected effect of beta-adrenergic blockade occurred, i.e. an increase both in volume and in pressure in diastole.

Subsequently (Swanton et al., 1977), we were able to show, using simultaneous pressure and volume measurements, that both practolol and propranolol produce a fall in diastolic change in pressure divided by change in volume, at the same, or at a lower mean left ventricular end-diastolic pressure, with the diastolic pressure/volume curve being shifted downwards and to the right. These results again suggested a decrease in muscle stiffness and an increase in diastolic distensibility.

Recently, using very similar techniques, Speiser \& Krayenbuhl (1981) have studied eight patients with hypertrophic cardiomyopathy. In three of them, diastolic distensibility appeared to increase but in the others it did not, and in the group as a whole betablockade did not affect the diastolic pressure-volume curve. The most likely explanation for these discrepant results is that, in some patients with hypertrophic cardiomyopathy, but not in others, beta-blockade is effective at improving diastolic distensibility. In support of the contention that beta-blockers can improve

(C) The Fellowship of Postgraduate Medicine, 1985 
diastolic distensibility, propranolol has been shown to reverse the slow diastolic closure rate of the mitral valve and to increase left ventricular systolic and enddiastolic dimensions in this condition (De la Calzada et al., 1976). Recent work digitizing both angiocardiograms and echocardiograms has shown delay in opening of the mitral valve and disturbance in the rate, duration, and coordination of all movement during filling, suggesting segmental abnormalities of left ventricular function (Sanderson et al., 1977, 1978).

The effect of beta-blockers on diastolic properties of the ventricle does not appear to be related to any change in metabolism, since we have shown that propranolol does not change lactate extraction significantly at any pacing rate, in either those patients with hypertrophic cardiomyopathy who can be shown to be ischaemic, or in a non-ischaemic group. We could not demonstrate a direct effect of propranolol upon myocardial metabolism in these patients.

The potential value of beta-blockade in hypertrophic patients with angina is thus probably to protect these patients from excessive increases in heart rate (Thompson et al., 1980).

\section{Ventricular relaxation}

We recently studied this by making high fidelity measurements of left ventricular pressure at increasing pacing rates in 21 patients with hypertrophic cardiomyopathy and a control group of 11 patients investigated for chest pain who proved to have normal hearts (Thompson et al., 1983). In both groups the fall in pressure during isovolumic relaxation from the point of min $\mathrm{dp} / \mathrm{dt}$ approximated closely to a monoexponential and could be described by a time constant and asymptote. The time constant shortened and the asymptote increased as heart rate rose in both groups, but the time constant was longer and min dp/dt less in the cardiomyopathy group than in the controls at all heart rates. In the cardiomyopathy patients, min $\mathrm{dp} /$ $\mathrm{dt}$, but not the time constant, was related to systolic pressure. During pacing, 8 cardiomyopathy patients developed metabolic evidence of myocardial ischaemia, but indices of relaxation did not differ between these 8 and the other 13, either at basal heart rate or at the highest pacing rate. In 10 cardiomyopathy patients measurements were repeated at comparable pacing rates after propranolol $(0.2 \mathrm{mg} /$ $\mathrm{kg}$ ). Left ventricular end-diastolic pressure and indices of contractility decreased after the drug but the time constant did not change. Eight patients received verapamil $(20 \mathrm{mg})$ after which there were substantial reductions in systolic pressure and contractility, but not in end-diastolic pressure. Min dp/dt decreased in proportion to systolic pressure but the time constant was unchanged. At the highest pacing rate before drug administration; three patients had abnormal lactate extraction which was corrected by either propranolol (1 patient) or verapamil (2 patients). Despite abolition of metabolic evidence of ischaemia, relaxation did not improve. We concluded that abnormal isovolumic relaxation is common in patients with hypertrophic cardiomyopathy but its severity correlates poorly with other features of the disease. Abnormal relaxation is not the result of ischaemia, and pressure-derived indices of relaxation do not improve after administration of either propranolol or verapamil.

\section{Regression of hypertrophy}

There is, to my knowledge, no report in the literature of propranolol causing regression of hypertrophy in the way that has been claimed for verapamil (Kaltenbach et al., 1979; Rosing et al., 1981).

\section{Arrhythmias}

Sudden death is the commonest form of termination in hypertrophic cardiomyopathy (Goodwin \& Krikler, 1976) and arrhythmias have recently received attention as a possible cause. Ambulatory electrocardiographic monitoring has shown a high incidence of arrhythmias often passing unnoticed by the patient (McKenna et al., 1980; Ingham et al., 1978). In both these studies, no reduction in arrhythmias was noted when propranolol was administered orally, though there is one report in the literature suggesting a protective effect of very large doses (Frank et al., 1978).

\section{References}

BRAUNWALD, E., MORROW, A.G., CORNELL, W.P., AYGEN, M.M. \& HILBISH, T.R. (1960). Idiopathic hypertrophic subaortic stenosis: clinical, hemodynamic and angiographic manifestations. American Journal of Medicine, 29, 924.

BRAUNWALD, E., LAMBREW, C.T., HARRISON, D.C. \& MORROW, A.G. (1964). In Cardiomyopathies Ciba Sym- posium, Wolstenholme, G.E.W. \& O'Connor, M. (eds). p. 172. Churchill: London.

DE LA CALZADA, C.S., ZIADY, G.M., HARDARSON, T., CURIEL, R. \& GOODWIN, J.F. (1976). Effect of acute administration of propranolol on ventricular function in hypertrophic obstructive cardiomyopathy measured by non-invasive techniques. British Heart Journal, 38, 794. 
FRANK, M.J., ABDULLA, A.M., CANEDO, M.I. \& SAYLESS, R.E. (1978). Long term medical management of hypertrophic obstructive cardiomyopathy. American Journal of Cardiology, 42, 993.

GOODWIN, J.F., SHAH, P.M., OAKLEY, C.M., COHEN, J. YIPINTSOI, T. \& POCOCK, W. (1964). In Cardiomyopathies Ciba Symposium, Wolstenholme, G.E.W. \& O'Connor, M. (eds). p. 189. Churchill: London.

GOODWIN, J.F. \& KRIKLER, D. (1976). Arrhythmia as a cause of sudden death in hypertrophic cardiomyopathy. Lancet, ii, 937.

INGHAM, R.E., MASON, J.W., ROSSEN, R.M., GOODMAN, D.J. \& HARRISON, D.C. (1978). Electrophysiologic findings in patients with idiopathic hypertrophic subaortic stenosis. American Journal of Cardiology, 41, 811.

KALTENBACH, M., HOPF, R., KOBER, G., BUSSMAN, D., KELBER, M. \& PETERSEN, Y. (1979). Treatment of hypertrophic obstructive cardiomyopathy with verapamil. British Heart Journal, 42, 35.

MCKENNA, W.J., CHETTY, S., OAKLEY, C.M. \& GOODWIN, J.F. (1980). Arrhythmia in hypertrophic cardiomyopathy; exercise and 48 hour ambulatory electro-cardiographic assessment with and without beta adrenergic blocking therapy. American Journal of Cardiology, 45, 1.

ROSING, D.R., CONDIT, J.R. MARON, B.J., KENT, K.M., LEON, M.B., BONOW, R.O., LIPSON, L.C. \& EPSTEIN, S.E. (1981). Verapamil therapy: a new approach to the pharmacologic treatment of hypertrophic cardiomyopathy. III. Effects of long term administration. American Journal of Cardiology, 48, 545.

SANDERSON, J.E., GIBSON, D.G., BROWN, D.J.\& GOODWIN, J.F. (1977). Left ventricular filling in hypertrophic cardiomyopathy. An echocardiographic study. British Heart Journal, 39, 661.

SANDERSON, J.E., TRAILL, T.A., ST. JOHN SUTTON, M.G., BROWN, D.J., GIBSON, D.G. \& GOODWIN, J.F. (1978). Left ventricular relaxation and filling in hypertrophic cardiomyopathy. British Heart Journal, 40, 596.

SPEISER, K.W. \& KRAYENBUHL, H.P. (1981). Reappraisal of the effect of acute beta-blockade on left ventricular filling dynamics in hypertrophic obstructive cardiomyopathy. European Heart Journal, 2, 21.

SWAN, D.A., BELL, B., OAKLEY, C.M. \& GOODWIN, J.F. (1971). Analysis of the symptomatic course and prognosis and treatment of hypertrophic obstructive cardiomyopathy. British Heart Journal, 33, 671.

SWANTON, B.H., BROOKSBY, I.A.B., JENKINS, B.S. \& WEBBPEPLOE, M.M. (1977). Haemodynamic studies of betablockade in hypertrophic obstructive cardiomyopathy. European Journal of Cardiology, 514, 327.

THOMPSON, D.S., NAQVI, M., JUUL, S.M., SWANTON, R.H., COLTART, D.J., JENKINS, D.S. \& WEBB-PEPLOE, M.M. (1980). Effects of propranolol on myocardial oxygen consumption. Substrate extraction and haemodynamics in hypertrophic cardiomyopathy. British Heart Journal, 44, 488.

THOMPSON, D.S., WILMSHURST, P., JUUL, S.M., WALDRON, C.B., JENKINS, B.S., COLTART, D.J. \& WEBBPEPLOE, M.M. (1983). Pressure derived indices of left ventricular isovolumic relaxation in patients with hypertrophic cardiomyopathy. British Heart Journal, 49, 259.

WEBB-PEPLOE, M.M., OAKLEY, C.M., CROXSON, R.S. \& GOODWIN, J.F. (1971). Cardioselective beta-adrenergic blockade in hypertrophic obstructive cardiomyopathy. Postgraduate Medical Journal, 47 (Suppl), 93.

WEBB-PEPLOE, M.M. (1974). In Cardiomyopathies Ciba Symposium, Wolstenholme, G.E.W. \& O'Connor, MO (eds). p. 103. Churchill: London.

WIGLE, E.D. (1964). In Cardiomyopathies Ciba Symposium Wolstenholme, G.E.W. \& O'Connor, M. (eds). p. 49? Churchill: London. 